Check for updates

Cite this: Mater. Adv., 2022, 3,381

Received 9th September 2021, Accepted 1st November 2021

DOI: $10.1039 / \mathrm{d} 1 \mathrm{ma00834}$

rsc.li/materials-advances

\section{Mitigating mass transport limitations: hierarchical nanoporous gold flow-through electrodes for electrochemical $\mathrm{CO}_{2}$ reduction}

\author{
Zhen Qi, (D)* Steven A. Hawks, (D) Corie Horwood, (D) Juergen Biener (D) and \\ Monika M. Biener (D)*
}

\begin{abstract}
The reaction rates for electrochemical $\mathrm{CO}_{2}$ reduction in aqueous electrolytes can be limited by the low concentration and diffusion rate of the reactant $\mathrm{CO}_{2}$. To overcome this limitation, we fabricated and tested hierarchical nanoporous gold (hnpAu) flow-through electrodes that enable pumping $\mathrm{CO}_{2}$ saturated potassium bicarbonate electrolyte directly through the macropores of hnpAu. The hnpAu flow-through electrode was fabricated by ink casting followed by annealing and dealloying to generate a bimodal pore distribution where macropores $(5-10 \mu \mathrm{m})$ act as flow channels and nanopores $(\sim 40 \mathrm{~nm})$ provide high surface area. To minimize local $\mathrm{CO}_{2}$ depletion at the electrolyte-electrode interface we selected flow rates that warranted diffusion lengths exceeding the macropore diameter dimensions. We observed that the $\mathrm{CO}_{2}$ reduction rate increases with increasing flow rate through the electrode, but even for the highest overpotentials and flow rates, less than $20 \%$ of the dissolved $\mathrm{CO}_{2}$ was utilized despite the absence of diffusion limitations. We find that the competing hydrogen evolution reaction becomes increasingly suppressed with increasing flow rate, specifically in the low overpotential regime. These observations suggest that, beyond diffusion limitations, the $\mathrm{CO}_{2}$ reduction rate in aqueous electrolytes may become limited by the availability of free reaction sites, and that flowing the electrolyte through the electrode increases the $\mathrm{CO}_{2}$ reduction rate by facilitating the removal of the $\mathrm{CO}$ product.
\end{abstract}

\section{Introduction}

Utilization of $\mathrm{CO}_{2}$ via electrochemical reduction using renewable energy has become a promising technology to close the anthropic $\mathrm{CO}_{2}$ emission cycle. ${ }^{1-6}$ As a consequence, much work has been devoted to developing more efficient catalysts for electrochemical $\mathrm{CO}_{2}$ reduction (ECR), but despite much progress in the field both catalyst energy efficiency and product selectivity still need to be improved. ${ }^{7-11}$ The majority of mechanistic studies on metal and metal alloy ECR catalysts have been performed in aqueous bicarbonate solutions, ${ }^{12-15}$ and often it has been found that the catalyst performance is limited by the availability of the reactant $\mathrm{CO}_{2}$ at the catalyst surface. At higher current densities, the low solubility and slow diffusion rate of $\mathrm{CO}_{2}$ in aqueous electrolytes lead to localized $\mathrm{CO}_{2}$ depletion at the electrode/electrolyte interface. ECR is operated in the potential region where the hydrogen evolution reaction (HER) and ECR are competing processes. Local pH gradients created by both HER and ECR further complicate catalyst evaluation by

Materials Science Division, Physical and Life Sciences Directorate, Lawrence Livermore National Laboratory, 7000 East Ave., Livermore, CA, 94550, USA. E-mail: qi2@llnl.gov,biener3@llnl.gov affecting the dissolved $\mathrm{CO}_{2}$ /bicarbonate equilibrium. Thus, to investigate the intrinsic catalyst reactivity, it would be beneficial to develop test conditions where diffusion limitations can be reduced or at least be controlled.

Early work revealed that mass transport, controlled by stirring, affects the ECR product distribution. ${ }^{16,17}$ More recently, inverse opal templated copper structures have been used to study the effect of mass transport in more detail, ${ }^{18}$ and it has been shown that thicker samples had a higher FE for HER due to mass transport limitations. Using copper nanowire catalyst coatings with different thickness as an example, Raciti et $a{ }^{13}{ }^{13}$ pointed out that mass transport effects need to be considered in the design of advanced ECR electrocatalysts. However, a rotating cylinder electrode study on $\mathrm{Cu}$ catalyzed $\mathrm{ECR}^{19}$ challenges the idea that the ECR faradaic efficiency (FE) can be improved by facilitating mass transport to reduce interfacial $\mathrm{pH}$ and $\mathrm{CO}_{2}$ gradients. Specifically, the observation that the HER becomes more predominant at higher rotation speeds has been explained by faster removal of $\mathrm{CO}$ adsorbed at the solid interface. By contrast, a more recent rotating ring disk electrode study on Au catalysed $\mathrm{ECR}^{20}$ suggests that the $\mathrm{FE}$ of the $\mathrm{CO}_{2}$-to-CO reduction increases with enhanced mass transport which in this study was attributed to the suppression of 
HER. Clearly, more work is needed to understand the various effects of mass transport on ECR. Here, a recently developed inverse rotating disk electrode ${ }^{21}$ that enables the use of gas chromatography may enable more detailed studies on the effect of mass transport. But regardless of these controversial results with regard of the effect of mass transport on ECR, it is generally accepted that the transport of the reactant $\mathrm{CO}_{2}$ limits the ECR current density that can be achieved in liquid electrolytes. Today the most promising approach to overcome this limitation is the use of gas diffusion electrodes (GDEs) $)^{22-28}$ that take advantage of the six orders of magnitude higher diffusivity of gas phase $\mathrm{CO}_{2}$ compared to $\mathrm{CO}_{2}$ dissolved in aqueous electrolytes. ${ }^{29}$ A variation of this concept are flow-through gas diffusion electrodes that recently have attracted increased attention as modelling and experimental studies on flowthrough gas diffusion electrodes for $\mathrm{ECR}^{30}$ and $\mathrm{N}_{2}$ reduction ${ }^{31}$ demonstrated significant electrolyzer performance improvements. Specifically, the flow-through concept further improves mass transport and enables suppression of HER through control of the water content in the catalyst layer. Specifically, a reduction of the boundary layer thickness, for example by increasing the flow-through rate, can dramatically increase the limiting current density. However, as promising as the GDE technology is, it may have limitations connected to efficient removal of lower volatility or ionic products which may lead to GDE flooding and/or catalyst degradation. ${ }^{32}$ This can be true even for microfluidic GDE electrolyzer designs with a catholyte flow field where it has been shown that lower volatility products such as ethanol can change the wetting behavior of the GDE leading to electrolyte penetration causing mass transport limitations. ${ }^{33}$

In this work, we explore the use of hierarchical nanoporous gold (hnpAu) liquid phase flow-through electrodes to control and eliminate the effects of diffusion limitations on ECR as outlined above. A gold catalyst was used for its well-known high selectivity for $\mathrm{CO}_{2}$-to-CO reduction which simplifies the gas product analysis. ${ }^{15,34-36}$ In our previous work on ERC in ionic liquids we demonstrated that implementing a liquid phase flow-through electrode approach can increase current density and faradaic efficiency for $\mathrm{CO}_{2}$-to-CO reduction by $7000 \%$ and $700 \%$, respectively. ${ }^{37}$ For the present study, we developed and tested hnpAu electrodes in a flow-through configuration in the well-defined environment of an H-cell (please refer to the experimental section for details of the testing setup). The hnpAu electrodes were fabricated by a combination of metallic ink casting and dealloying using our previously developed $\mathrm{Ag}$ $\mathrm{Au}$ inks. ${ }^{38}$ Decomposition of the polymeric binder of the $\mathrm{Ag}-\mathrm{Au}$ particle inks during heating the casted green body to $850{ }^{\circ} \mathrm{C}$ for 12 hours generates the macroporosity required for the flowthrough electrode configuration; dealloying then introduces the characteristic nanoscale porosity of npAu that provides the macroporous walls with high surface area. We observe that the effect of flow via pumping a $\mathrm{CO}_{2}$ saturated electrolyte through the electrode improves the ECR selectivity upon application of higher flow rates, especially in the low overpotential region.

\section{Results and discussion}

Electrode fabrication and structure characterization of flowthrough hierarchical nanoporous gold

A schematic diagram of the liquid flow-through electrode and its integration into the H-cell setup is shown in Fig. 1a and b. More details regarding the fabrication and integration of the flow-through electrode into the H-cell setup the can be found in the experimental section, and additional information about the microstructure of hnpAu fabricated by our $\mathrm{Ag}-\mathrm{Au}$ ink technology can be found in our previous work. ${ }^{38}$ Because the hnpAu electrodes (Fig. 1c) used in this work were cast instead of 3D printed they have only two characteristic length scales: micronsized pores, resulting from the removal of the polymeric binder and water in the $\mathrm{Au}-\mathrm{Ag}$ ink during drying and annealing, and nanoscale porosity formed by dealloying. During the annealing step, the micron-sized $\mathrm{Ag}$ and $\mathrm{Au}$ particles of the $\mathrm{Au}-\mathrm{Ag}$ ink form a homogeneous AgAu alloy through solid state diffusion resulting in a micron-scale facetted monolithic surface morphology (Fig. 1c). Subsequent dealloying in concentrated nitric acid selectively leached $\mathrm{Ag}$ from the AgAu alloy resulting in the formation of a uniform nanoporosity (Fig. 1c, inset) with a characteristic pore/ligament length scale of $\sim 40 \mathrm{~nm}$. The micro-scale porosity of this hierarchical morphology enables flow-through rates in the $\mathrm{ml} \mathrm{min}^{-1}$ range at sub-atmospheric a
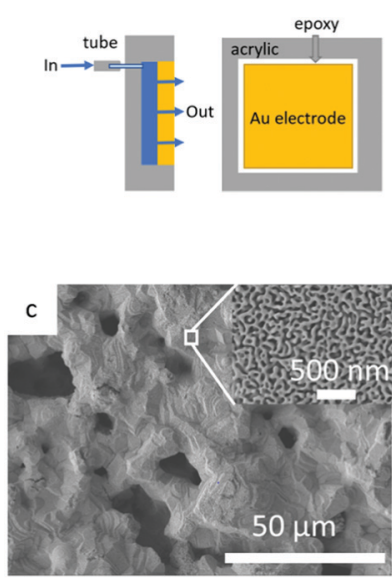

$b$

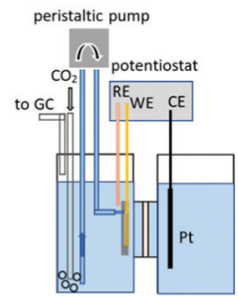

d

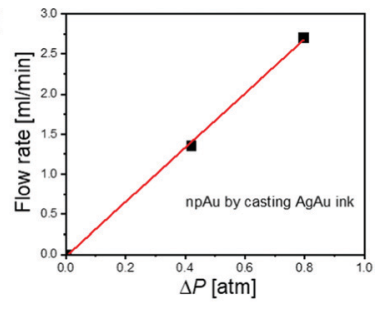

Fig. 1 Schematic diagram showing the design of the liquid flow-through electrode and its integration into the $\mathrm{H}$-cell setup. (a) Side and front view of flow-through electrode setup: epoxy was used to attach and seal the $1 \times 1 \times 0.1 \mathrm{~cm}^{3}$ hierarchical nanoporous gold electrode in an acrylic casing. A tube on the backside near the top edge of the acrylic casing serves as an inlet for the flow-through electrode and a spacer on the inlet side warrants uniform distribution of the flow across the electrode; (b) integration of the flow-through electrode assembly into a $\mathrm{H}$-cell setup using a peristaltic pump to cycle the saturated $\mathrm{CO}_{2}$ solution from the cathodic cell through the electrode. $\mathrm{CO}_{2}$ gas was bubbled through the cathodic compartment of the $\mathrm{H}$-cell at a rate of $30 \mathrm{sccm}$ to guarantee saturation of the electrolyte with $\mathrm{CO}_{2}$ and carry gas phase products to the GC. (c) SEM micrographs showing the microstructure of a hierarchical nanoporous gold electrode. The inset shows the nanoscale ligament morphology of the macropore cell wall; (d) pressure drop vs. flow rate of the hierarchical nanoporous gold electrode prepared by ink casting. 
pressure gradients across the hnpAu electrode (see below); the integrated nanoscale porosity provides high surface area for high catalytic activity. Based on the gold oxidation/reduction surface area measurement reported in our previous work, ${ }^{38}$ the electrochemically active surface area of our npAu flow-through electrode is $4.7 \mathrm{~m}^{2} \mathrm{~g}^{-1}$.

The permeability of the hnpAu electrode was evaluated through the pressure drop measurements (Fig. 1d) described in the experimental section. It was observed that the pressure drop increases linearly with the flow rate confirming the interconnected nature of the macropores of the casted hnpAu. The flow rate through our one-square-centimeter footprint and one-millimeter-thick hnpAu flow-through electrode was $3.25 \mathrm{ml} \mathrm{min} \mathrm{min}^{-1}$ at $1 \mathrm{~atm}$ pressure drop across the electrode (Fig. 1d). This gives an approximate fluid permeability of 5.4 using Darcy's law. Despite using a $\sim 10 \times$ larger pressure drop across the hnpAu membrane, the highest flow rate is about 10 times smaller than the highest flow rate used in previous experiments with 3D printed hnpAu membranes. ${ }^{38}$ We attribute the lower conductance of the ink-cast hnpAu membranes to the absence of the printed 100 micron-scale porosity in 3D printed hnpAu which reduces the macroscale porosity to $\sim 0.3$ compared to $\sim 0.9$ for $3 \mathrm{D}$ printed hnpAu.

\section{Electrochemical $\mathrm{CO}_{2}$ reduction under different flow rates}

Based on the pressure drop measurements described above, we chose three different flow rates, $0.32,0.64$, and $1.28 \mathrm{ml} \mathrm{min}^{-1}$, to study the effect of pressure gradient driven mass transport on ECR performance (Fig. 2). The following trends were observed: (i) for all flow rates, the total current density as well as the $\mathrm{CO}$ and $\mathrm{H}_{2}$ specific current densities increase as expected with increasing overpotential. The total current density was relatively independent of the flow rate, with less than
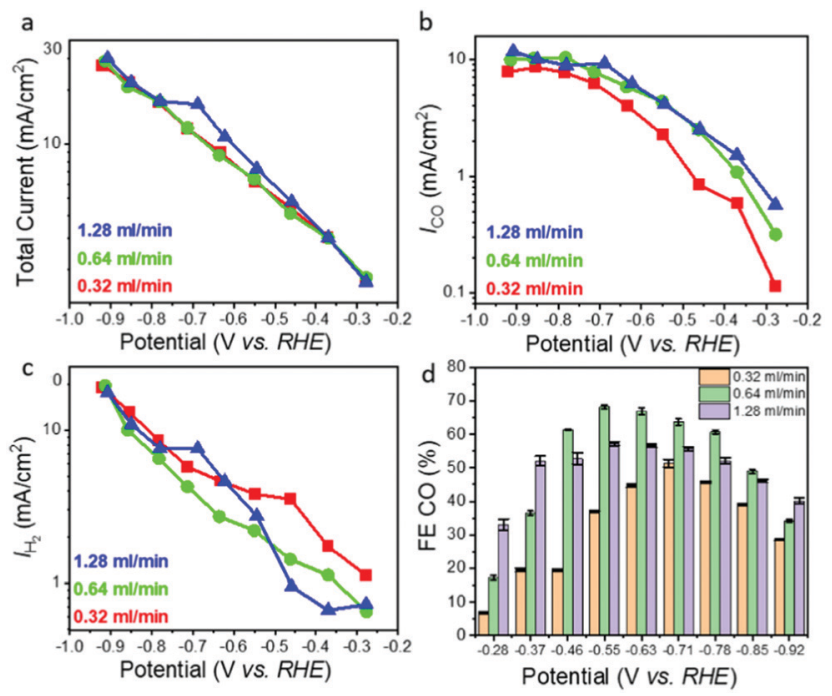

Fig. 2 Electrochemical $\mathrm{CO}_{2}$ reduction using an ink-cast hierarchical nanoporous gold flow-through electrode at three different flow rates ranging from 0.32 to $1.28 \mathrm{ml} \mathrm{min}^{-1}$ : total current density (a) as well as $\mathrm{CO}$ (b), $\mathrm{H}_{2}$ (c) specific current densities and (d) FE for $\mathrm{CO}$
20 percent variation between the different flow rates for any given overpotential (Fig. 2a); (ii) the $\mathrm{CO}_{2}$-to-CO specific current density (Fig. 2b) increased for all overpotentials with increasing flow rate (from 0.32 to $1.28 \mathrm{ml} \mathrm{min}^{-1}$ ) but seems to saturate at high overpotentials; and (iii) the HER related current density increased exponentially with increasing overpotential but decreased with increasing flow rate (Fig. 2c). The effect of flow rate is more pronounced in the low overpotential region (below $-0.6 \mathrm{~V}$ vs. RHE) where the CO specific current density at highest flow rate of $1.28 \mathrm{ml} \mathrm{min}^{-1}$ is up to 5 times higher than that measured the lowest flow rate of $0.32 \mathrm{ml} \mathrm{min}^{-1}$ (Fig. 2b). The corresponding $\mathrm{H}_{2}$ specific current density (Fig. 2c) shows the opposite trend revealing suppression of HER with increasing flow rate. At higher overpotentials (above $-0.6 \mathrm{~V}$ vs. RHE) the $\mathrm{CO}$ and $\mathrm{H}_{2}$ specific current densities show a much weaker dependence on the flow rate than in the low overpotential region (Fig. 2b and c) although the trends remain the same, that is, the CO specific current density increases while the $\mathrm{H}_{2}$ specific current density decreases with increasing flow rate. For the highest overpotentials the CO specific current density increases only by $\sim 50 \%$ if the flow rate (and thus the reactant $\mathrm{CO}_{2}$ supply) is increased by a factor of 4 . The trends described above are very stable and reproducible, with less than $1 \%$ variation (in terms of current densities) between repeat experiments performed with the same hnpAu flow-through electrode assembly after several weeks. Finally, it is interesting to note that the hnpAu catalyst flow-through electrode studied in this work shows lower CO FEs compared to those observed on very similar npAu catalyst surfaces in previous ECR studies. ${ }^{15,39}$ Especially oxide derived npAu catalysts with its smaller feature size nanoporosity provided CO FEs near $100 \%$ over a wide range of applied potentials. ${ }^{15}$ Higher CO FEs up to 80\%@100 $\mathrm{mA} \mathrm{cm}^{-2}$ were also observed on $\mathrm{npAu}$ coated GDEs. ${ }^{39}$ The lower CO FEs as shown in Fig. 2d (maximum FE for CO of $\sim 70 \% @ 5 \mathrm{~mA} \mathrm{~cm} \mathrm{~cm}^{-2}$ ) observed in the present study thus seem to be a consequence of the flow-through operation modus rather than reflecting the activity and selectivity of the npAu catalyst surface itself, most likely related to the different microenvironment created by the flow-through operation.

\section{Discussion of the effect of flow on electrochemical $\mathrm{CO}_{2}$ reduction}

Neglecting $\mathrm{pH}$ induced changes in the $\mathrm{CO}_{2} / \mathrm{HCO}_{3}{ }^{-}$equilibrium, the concentration of the reactant $\mathrm{CO}_{2}$ dissolved in the electrolyte at the electrode exit, and corresponding average $\mathrm{CO}_{2}$ depletion while passing through the flow-through electrode, can be calculated from the residence time $\tau$ of the electrolyte in the electrode and the measured CO specific current (Fig. 3a and b). Here, the residence time $\tau$ is defined as the ratio of the macropore volume (only the macropores contribute to flow) to the flow rate $\left(0.34-1.28 \mathrm{ml} \mathrm{min}^{-1}\right)$. The macropore volume is the macropore porosity times the electrode volume $(0.3 \times$ $0.1 \mathrm{ml}=0.03 \mathrm{ml}$ in the present case). For the flow rate range used in this work, the residence time thus is between $1.3 \mathrm{~s}$ $\left(1.28 \mathrm{ml} \mathrm{min}^{-1}\right)$ and $5.3 \mathrm{~s}\left(0.32 \mathrm{ml} \mathrm{min}^{-1}\right)$. Neglecting additional $\mathrm{CO}_{2}$ consumption by ECR and HER induced $\mathrm{pH}$ changes, 
a
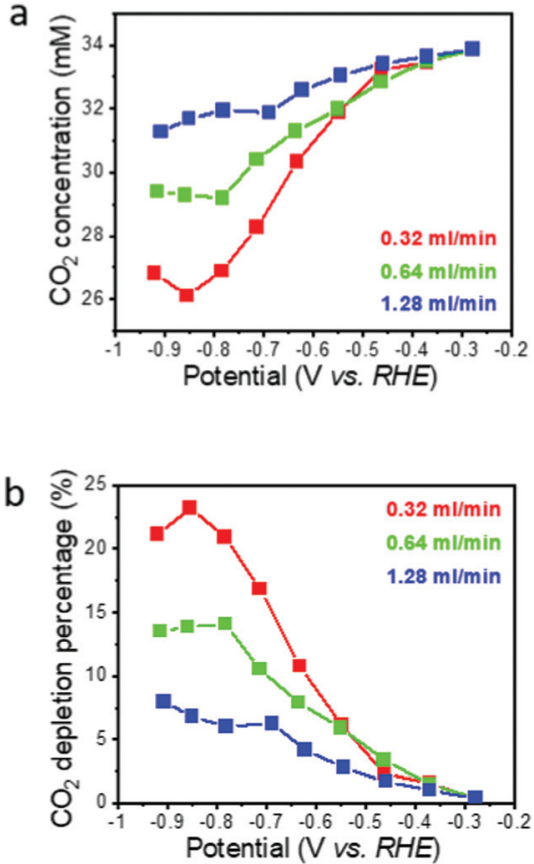

Fig. 3 Calculated $\mathrm{CO}_{2}$ concentration (a) and corresponding $\mathrm{CO}_{2}$ depletion (b) on the flow through electrode exit side as a function of potential and electrolyte flow rate.

the calculated $\mathrm{CO}_{2}$ depletion is less than $10 \%$ for the highest flow rate (Fig. 3b), even at the highest overpotential where the CO specific current density is the highest. For the lowest flow rate, the $\mathrm{CO}_{2}$ depletion reaches a maximum of about $24 \%$, but stays below $10 \%$ in the low overpotential region. While this calculation demonstrates that the global $\mathrm{CO}_{2}$ depletion in the electrolyte stayed moderately low for most operating conditions, it does not capture local $\mathrm{CO}_{2}$ depletion at the electrode/ electrolyte interface. The assumption that $\mathrm{CO}_{2}$ consumption by ECR and HER induced $\mathrm{pH}$ changes can be neglected seems to be reasonable in view of the slow rate of the first step of the $\mathrm{CO}_{2}$ to bicarbonate reaction under near $\mathrm{pH}$ neutral conditions where the $\mathrm{CO}_{2}$ hydrogenation is at least 4 times slower compared to even the longest electrolyte residence time in our hnpAu flow-through electrode $(\sim 20 \mathrm{~s} v s .5 \mathrm{~s}) .{ }^{40}$

The degree of local $\mathrm{CO}_{2}$ depletion at the macropore surface, again neglecting $\mathrm{pH}$ induced changes of the $\mathrm{CO}_{2} / \mathrm{HCO}_{3}{ }^{-}$equilibrium, can be estimated from the diffusion length with respect to the macropore dimension. The diffusion length, $L$, is given by Fick's law, $L=\sqrt{2 D \cdot t}$, where $D$ is the diffusion coefficient ( $0.0016 \mathrm{~mm}^{2} \mathrm{~s}^{-1}$ for $\mathrm{CO}_{2}$ in aqueous solution), ${ }^{29}$ and $t$ is diffusion time. Inserting the residence times $\tau(1.3-5.3 \mathrm{~s})$ calculated above yields diffusion lengths of 130,91 , and $65 \mu \mathrm{m}$ for $0.32,0.64$, and $1.28 \mathrm{ml} \mathrm{min}{ }^{-1}$, respectively. Thus, even for the shortest residence time (highest flow rate) the diffusion length is larger than the typical macropore dimension in our hnpAu flow-through electrodes (Fig. 1c). This indicates that radial diffusion within the macropores is fast on the residence time scale thus avoiding concentration gradients and local $\mathrm{CO}_{2}$ depletion zones within the macropores. The tortuous morphology of the macroporous system is expected to further facilitate mixing of the electrolyte thus mitigating any remaining concentration gradients while passing through the flow-through electrode. Such a beneficial effect of a tortuous, branching pore morphology on transport properties has been recently demonstrated by fluid dynamics simulations on various heat exchanger designs. ${ }^{41}$ However, even though diffusion limitations in the flow-through electrode can be ruled out under the chosen operation conditions, the ECR related current density seems to saturate in the limit of high overpotentials indicating operation in a limiting current regime. As the current density in the limit of high overpotentials depends only weakly on the flow rate, the current density does not seem to be limited by the $\mathrm{CO}_{2}$ supply but rather by the reaction rate. In this context it is important to note that the npAu morphology is generally highly active for ECR as CO FEs up to $80 \% @ 100 \mathrm{~mA} \mathrm{~cm}^{-2}$ have been observed on npAu coated GDE's. ${ }^{39} \mathrm{NpAu}$ catalysts have a nanoscale morphology consisting of high-surface-curvature Au ligaments which provide a high density of low-coordination number stepedge and kink sites that are more reactive than terrace sites characteristic for planar Au electrodes. ${ }^{42}$

The conclusion that depletion zones are not the root cause of the limiting current behavior is further supported by the theoretically predicted limiting current density $i_{\mathrm{L}}$ that can be calculated from the depletion layer thickness $\delta^{43}$ which, per definition, for our flow-through electrode cannot be thicker than the average macropore radius $(\sim 10 \mu \mathrm{m}$ for hnpAu):

$$
i_{\mathrm{L}}=\frac{n F D C_{\mathrm{CO}_{2}}^{*}}{\delta}
$$

Here, $n$ is the number of electrons transferred ( 2 for $\mathrm{CO}_{2}$-to-CO reduction), $F$ is the Faraday constant (96 $485 \mathrm{As} \mathrm{mol}^{-1}$ ), $D$ is the diffusion constant $\left(1.6 \times 10^{-5} \mathrm{~cm}^{2} \mathrm{~s}^{-1}\right),{ }^{44}$ and $C_{\mathrm{CO}_{2}}^{*}$ is the $\mathrm{CO}_{2}$ bulk concentration ( $30 \mathrm{mM})$. According to eqn (2), the limiting current density of $20 \mu \mathrm{m}$ diameter pores under flow-through conditions is approximately $90 \mathrm{~mA} \mathrm{~cm}{ }^{-2}$. As the projected macropore surface area of our npAu electrode is $\sim 60 \mathrm{~cm}^{2}$ (assuming that straight cylindrical $20 \mu \mathrm{m}$-diameter pores account for the macropore porosity of 0.3 ), the theoretically predicted limiting current density of our 3D hnpAu flowthrough electrode is $\sim 5$ A per square centimeter footprint of the flow-through electrode, many times larger than maximum current density of $0.12 \mathrm{~A} \mathrm{~cm}^{-2}$ electrode footprint area calculated for the highest flow rate $\left(1.28 \mathrm{ml} \mathrm{min}^{-1}\right)$ assuming $100 \%$ $\mathrm{CO}_{2}$-to-CO conversion.

Thus, neither global nor local (at the electrode/electrolyte interface) $\mathrm{CO}_{2}$ depletion can explain relatively small effect of flow rate on the observed ECR/HER current densities in the limit of high over potentials. For example, the CO specific current density for the highest flow rate/highest overpotential combination increases by only $50 \%$ with respect to the corresponding lowest flow rate and global $\mathrm{CO}_{2}$ depletion decreases to $10 \%$. The question remains why only a small fraction of the $4 \times$ higher $\mathrm{CO}_{2}$ supply is utilized even when diffusion limitations can be ruled out? The analysis above seems to rule out 
that the CO specific current density and selectivity are limited by the diffusion of the reactant $\mathrm{CO}_{2}$.

Besides diffusion limitations, the experimentally observed flow-rate dependent changes in the CO and HER specific current densities can potentially be caused by local $\mathrm{pH}$ changes. Both ERC $\left(\mathrm{CO}_{2}+2 \mathrm{H}^{+}+2 \mathrm{e}^{-} \rightarrow \mathrm{CO}+\mathrm{H}_{2} \mathrm{O}\right)$ and HER $\left(2 \mathrm{H}^{+}+\right.$ $2 \mathrm{e}^{-} \rightarrow \mathrm{H}_{2}$ ) consume protons which, especially for higher current densities, increases the local $\mathrm{pH}$ at the electrode/ electrolyte interface. A higher $\mathrm{pH}$ value can affect the ECR process by (i) shifting the $\mathrm{CO}_{2} / \mathrm{HCO}_{3}{ }^{-} / \mathrm{CO}_{3}{ }^{2-}$ equilibrium towards $\mathrm{HCO}_{3}{ }^{-}$and $\mathrm{CO}_{3}{ }^{2-}$ thus effectively consuming of free $\mathrm{CO}_{2}$ which reduces the selectivity towards ECR; ${ }^{45,46}$ (ii) by affecting the surface coverages of adsorbed ${ }^{*} \mathrm{CO}$ and ${ }^{*} \mathrm{H}$ intermediates; and (iii) by suppressing HER. ${ }^{47}$ Indeed, the highest calculated $\mathrm{CO}_{2}$ depletion of $24 \%$ at the lowest flow rate

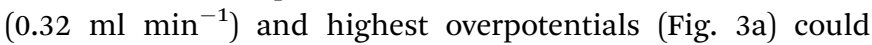
significantly increase if the $\mathrm{pH}$ increases above the equilibrium value of 6.8. ${ }^{13}$ The $\mathrm{pH}$ effects should become more pronounced for the combination of high overpotentials and low flow rates where ECR and HER current densities are high and the electrolyte exchange is slow. However, as discussed above, in view of the slow rate of the first step of the $\mathrm{CO}_{2}$ to bicarbonate reaction under near $\mathrm{pH}$ neutral conditions ${ }^{40}$ and the short electrolyte residence times under our experimental conditions, $\mathrm{CO}_{2}$ consumption by local $\mathrm{pH}$ changes does not seem to be an important factor. This conclusion is further corroborated by the observation that the effect of flow rate on ECR and HER rates is most pronounced in the low overpotential region where the current densities are small, and the $\mathrm{pH}$ can thus be expected to be more stable. Thus, while it is tempting to attribute the suppression of HER to an increase of the local $\mathrm{pH}$, the counter intuitive flow rate dependency hints towards a more complicated picture where the rate also depends on the availability of free catalytic sites. Au is an excellent catalyst for electrochemical $\mathrm{CO}_{2}$-to-CO reduction due to its low $\mathrm{CO}$ adsorption energy which facilitates the desorption of the product $\mathrm{CO}$ which is a known catalyst poison. ${ }^{48}$ We hypothesize that higher flow-rates facilitate the removal of the product and catalyst poison $\mathrm{CO}$ thus increasing the number of free reaction sites available for ECR.

\section{One electron ferricyanide reduction}

To further test the effectiveness of the flow-through electrode approach, we explored the effect of flow rate on ferricyanide reduction, which is a simple one-electron inner sphere electrode reaction ${ }^{49}$ without the complications of the ECR system that arise from $\mathrm{pH}$-induced changes of the $\mathrm{CO}_{2} / \mathrm{HCO}_{3}{ }^{-} / \mathrm{CO}_{3}{ }^{2-}$ equilibrium or catalyst poisoning by the reaction product $\mathrm{CO}$. Thus, ferricyanide reduction is frequently used in the field to assess cell hydrodynamics such as boundary layer thickness versus flow rate. ${ }^{50}$ We used a $30 \mathrm{mM}$ potassium ferricyanide in $1 \mathrm{M} \mathrm{KCl}$ supporting electrolyte solution to mimic the solubility of $\mathrm{CO}_{2}$ in aqueous solution. The flow rate dependence of the reduction current was tested in the diffusion limited regime at a constant potential at $-0.3 \mathrm{~V}$ vs. $\mathrm{Ag} / \mathrm{AgCl}$ (Fig. 4a). The $\mathrm{K}_{3}\left[\mathrm{Fe}(\mathrm{CN})_{6}\right]$ reduction current increases as expected with
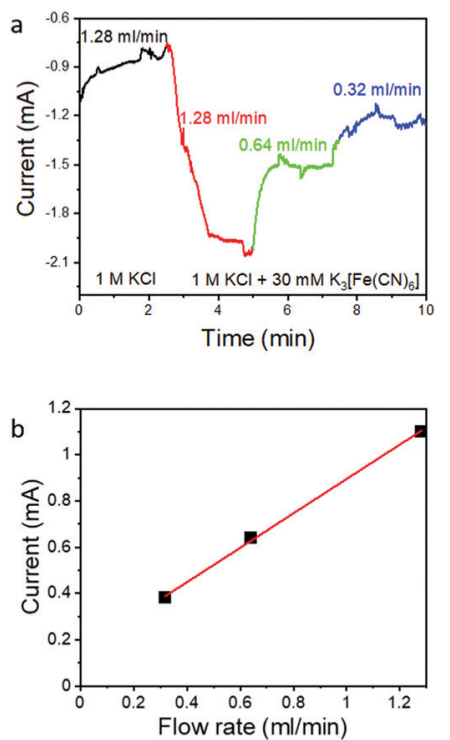

Fig. 4 Ferricyanide reduction current vs. time using the hierarchical nanoporous gold flow-through electrode at $-0.3 \mathrm{~V}(\mathrm{vs}$. $\mathrm{Ag} / \mathrm{AgCl}$ ) in $30 \mathrm{mM} \mathrm{K}_{3}\left[\mathrm{Fe}(\mathrm{CN})_{6}\right]$ in $1 \mathrm{M} \mathrm{KCl}$ supporting electrolyte at three different flow rates (a). Flow rate versus current at different flow rates showing its linear relationship (b).

increasing flow rate as more ferricyanide becomes available. The current density increases linearly with the flow rate, but only $\sim 2 \%$ of the available $\mathrm{K}_{3}\left[\mathrm{Fe}(\mathrm{CN})_{6}\right]$ is consumed in a single pass (Table 1$)$. The lower utilization of $\mathrm{Fe}(\mathrm{CN})_{6}{ }^{3-}$ compared to $\mathrm{CO}_{2}$ may be caused by a weaker interaction of $\mathrm{Fe}(\mathrm{CN})_{6}{ }^{3-}$ with the $\mathrm{Au}$ surface compared to $\mathrm{CO}_{2}$ (inner sphere electrode reactions require strong interaction with the electrode) and the lower diffusion constant of the ferricyanide ion in aqueous solution $\left(0.0007 \mathrm{~mm}^{2} \mathrm{~s}^{-1}\right)^{51}$ which makes this system more prone to local depletion.

But independent from the lower utilization of ferricyanide compared to $\mathrm{CO}_{2}$, the linear increase of the ferricyanide reduction current with increasing flow rate (as shown in Fig. 4b) confirms that the flow through electrode approach can indeed be used to increase electrochemical conversion currents. In case of ECR at high overpotentials, the CO specific current does not increase linearly with the flow rate even though the combination of residence time (controlled by the flow rate) and the characteristic macropore dimensions of hnpAu should have prevented even local depletion at the electrolyte/electrode interface. So while the $50 \%$ increase in

Table 1 Flow rates, average current, calculated ferricyanide consumed, ferricyanide available, and actual consumption percentage in $30 \mathrm{mM}$ $\mathrm{K}_{3}\left[\mathrm{Fe}(\mathrm{CN})_{6}\right]+1 \mathrm{M} \mathrm{KCl}$

\begin{tabular}{|c|c|c|c|c|}
\hline $\begin{array}{l}\text { Flow rate } \\
\left(\mathrm{ml} \mathrm{min}^{-1}\right)\end{array}$ & $\begin{array}{l}\text { Average } \\
\text { current } \\
\text { measured } \\
(\mathrm{mA})\end{array}$ & $\begin{array}{l}\text { Ferricyanide } \\
\text { consumed } \\
\left(\mathrm{mol} \mathrm{s}^{-1}\right)\end{array}$ & $\begin{array}{l}\text { Ferricyanide } \\
\text { available } \\
\left(\mathrm{mol} \mathrm{s}^{-1}\right)\end{array}$ & $\begin{array}{l}\text { Consumption } \\
(\%)\end{array}$ \\
\hline 0.32 & 0.38 & $3.93 \times 10^{-9}$ & $1.68 \times 10^{-7}$ & 2.3 \\
\hline 0.64 & 0.64 & $6.63 \times 10^{-9}$ & $3.37 \times 10^{-7}$ & 1.9 \\
\hline 1.28 & 1.10 & $1.13 \times 10^{-8}$ & $6.75 \times 10^{-6}$ & 1.7 \\
\hline
\end{tabular}


the $\mathrm{CO}_{2}$ reduction rate (from $8 \mathrm{~mA} \mathrm{~cm}{ }^{-2}$ at $0.32 \mathrm{ml} \mathrm{min}^{-1}$ to $12 \mathrm{~mA} \mathrm{~cm}{ }^{-2}$ at $0.128 \mathrm{ml} \mathrm{min}^{-1}$ ) at the highest overpotential $(-0.925 \mathrm{~V})$ can be attributed to the improved mass transport, ECR seems to be a much more complex reaction; in addition to $\mathrm{CO}_{2}$ supply, the overall reaction rate depends on the availability of free reaction sites, competition between ERC and HER, and the equilibrium between $\mathrm{CO}_{2}$ and the bicarbonate solution, all of which are interconnected and $\mathrm{pH}$ dependent. The current results suggest that understanding and controlling the interplay among $\mathrm{CO}_{2}$ concentration, $\mathrm{pH}$, and $\mathrm{CO}_{2} / \mathrm{HCO}_{3}{ }^{-} / \mathrm{CO}_{3}{ }^{2-}$ equilibrium is the key to maintain high CO FEs. By using a flow through electrode and conditions which result in diffusion lengths much greater than the macropore dimensions, we can rule out global and local depletion as a limitation. Furthermore, the flow rate dependency on the ECR-HER competition seems to rule out local $\mathrm{pH}$ changes as deciding factor. We also can rule out that the activity of npAu prepared by dealloying too low to sustain higher $\mathrm{CO}_{2}$-to-CO specific current densities as high CO FEs up to $80 \% @ 100 \mathrm{~mA} \mathrm{~cm} \mathrm{~cm}^{-2}$ were observed in previous work on npAu coated GDEs. ${ }^{39}$ This leaves the availability of free reaction sites as a dominating factor limiting the ECR rate beyond diffusion limitations.

\section{Conclusion}

We fabricated, integrated, and tested a hnpAu catalyst liquid phase flow-through electrode for electrochemical $\mathrm{CO}_{2}$-to-CO reduction. The results demonstrate that the flow-through configuration can improve the faradaic efficiency of the $\mathrm{CO}_{2}$ to- $\mathrm{CO}$ reduction, but also shows that the increase in the $\mathrm{CO}_{2}$ reduction rate lacks behind the increase in reactant supply with increasing flow rate despite carefully matching flow rate, pore size and diffusion length to rule out global and local $\mathrm{CO}_{2}$ depletion as well as diffusion limitations. The effect of flow rate is most pronounced in the low overpotential region (below $-0.6 \mathrm{~V}$ vs. RHE) where the CO specific current density at highest flow rate $\left(1.28 \mathrm{ml} \mathrm{min} \mathrm{m}^{-1}\right)$ is up to $2-5$ times higher compared to that measured at the lowest flow rate (0.32 $\mathrm{ml} \mathrm{min}^{-1}$ ) although the low ECR and HER rates in this potential region are not expected to cause local $\mathrm{CO}_{2}$ depletion or $\mathrm{pH}$ changes, even at the lowest flow rate. The HER related current density shows the opposite trend and decreases with increasing flow rate. At higher overpotentials (above $-0.6 \mathrm{~V} v s$. RHE) the CO specific current density increases more slowly with increasing flow rate despite the much higher reaction rates in this potential region. $\mathrm{CO}_{2}$ depletion can be ruled out as limiting factor as it remains below $10 \%$ for the highest flow rate/overpotential combination leaving plenty of room for higher ECR rates. While ECR and HER induced $\mathrm{pH}$ changes are expected to affect the ECR performance, the more pronounced HER suppression in the low overpotential region seems to indicate that the ECR performance is dominated by other effects. Here, we speculate that besides increasing the $\mathrm{CO}_{2}$ supply, an increase in the flow rate benefits the ECR performance by facilitating the removal of the product CO thus increasing the number of available catalytic sites. More broadly, the effectiveness of $\mathrm{CO}$ removal might be a more important factor than generally assumed in determining the performance of an ECR electrolyzer configuration. Specifically, it might explain why npAu coated GDEs ${ }^{39}$ can sustain much higher ECR current densities than the flow-through ECR electrode configuration described in this work as our analysis shows that, like a GDE, our flow-through ECR electrode is very effective in supplying $\mathrm{CO}_{2}$. In absence of bubble formation, the $\mathrm{CO}$ removal in a flow-through electrode requires that the produced CO dissolves in the electrolyte which is limited by the 40 times lower solubility of $\mathrm{CO}$ in water compared to that of $\mathrm{CO}_{2} \cdot{ }^{52}$ By contrast, the GDE configuration allows transport of CO through the gas phase thus making this process much more efficient. We note that we also tested thick metal foam electrodes in a GDE environment and observed poor performance due to insufficient water management (unpublished results). Finally, a related but different reason for the lower-thanexpected ECR current density of our flow-through electrode design in the absence of $\mathrm{CO}_{2}$ transport limitations might be the presence of electrolyte related strongly adsorbed species like carbonate or bicarbonate anions that can poison the active sites but are not present in the GDE configuration.

Despite the lower-than-expected ECR related current density, accompanying tests with the simple one-electron transfer ferricyanide reduction reaction show the expected linear increase in current density with the flow rate, thus confirming the validity of the liquid phase flow-through electrode design concept and further demonstrating that factors other than the $\mathrm{CO}_{2}$ supply control the ECR rate in aqueous electrolytes at high current densities and flow rates.

In conclusion, we believe that this work provides new insight into ECR under flow-through conditions and will help to improve the design of ECR reactors. While we studied the ECR performance of flow-through electrodes on the $\mathrm{CO}_{2}$-to$\mathrm{CO}$ reaction because of its simplicity regarding product analysis, the flow through electrode technology is geared towards ECR products that are less volatile (C2-C3 products or higher) or less soluble (formate) where operation in a liquid electrolyte may become advantageous over GDE technologies.

\section{Experimental}

\section{Ag-Au ink preparation}

As previously reported, ${ }^{38} \mathrm{Ag}-\mathrm{Au}$ inks with a $\sim 2: 1 \mathrm{Ag}$ to $\mathrm{Au}$ atomic ratio were prepared by mixing $5 \mathrm{~g}$ of $\mathrm{Ag}$ clay $[90 \mathrm{wt} \%$ silver powder $+10 \mathrm{wt} \%$ water and organic binder, precious metal clay (PMC), Mitsubishi Materials] with $5 \mathrm{~g}$ of Au clay (91.7 wt\% pure gold $+8.3 \mathrm{wt} \%$ organic binder, water, and silver; PMC, Mitsubishi Materials) and 0.5 to $1.0 \mathrm{~g}$ of water (Millipore). In this work we explored a casting technique thus avoiding the more time-consuming 3D printing process used in previous work: the ink was directly casted into a laser cut mold $\left(10 \times 10 \times 1 \mathrm{~mm}^{3}\right)$, and a gold wire with a diameter of $1 \mathrm{~mm}$ was imbedded in the ink to serve as a current collector. 
The green body, obtained by drying the cast ink at room temperature for one day, was heated in a muffle furnace at $850{ }^{\circ} \mathrm{C}$ for 12 hours to form a uniform $\mathrm{AgAu}$ alloy while simultaneously removing the remaining polymeric binders and water. Dealloying was performed in concentrated (68 wt\%) $\mathrm{HNO}_{3}$ (ACS, VWR) for 5 days. Scanning Electron Microscopy (Jeol 7410 with lower secondary electron detector, accelerating voltage of $5 \mathrm{keV}$ and a working distance of $8 \mathrm{~mm}$ ) confirmed the hierarchical porosity generated by the ink casting/dealloying approach.

\section{Flow-through electrode assembly and pressure drop test}

The hnpAu disks were glued with epoxy (Torr Seal) into a sealed acrylic frame. A tube on the backside of the acrylic frame allows flowing of the electrolyte through the hnpAu sample (Fig. 1a). A spacer between the hnpAu sample and the acrylic back plate of the frame ensured a uniform flow field within this flowthrough electrode assembly. The transport properties of this setup were assessed by measuring the pressure drop across the cell using a pressure transducer (Omega, PX209, 200g5v, detection range of 0 to $103.4 \mathrm{kPa}$ ) connected to the cell inlet while pumping (WatsonMarlow 120, pumping speed up to $27 \mathrm{ml} \mathrm{min}^{-1}$ ) the aqueous electrolyte at different flow rates through the cell.

\section{ECR test}

ECR tests were performed in a customized H-cell $(80 \mathrm{ml}$ volume per chamber, Adams \& Chittenden Scientific Glass) with a lowprofile $\mathrm{Ag} / \mathrm{AgCl}$ (6 $\mathrm{mm}$ in diameter, Pine research) reference electrode. An anion exchange membrane (Fumasep, FKS-PET75) was used to separate the cathode and anode compartments. $60 \mathrm{ml}$ of $0.1 \mathrm{M} \mathrm{KHCO}_{3}$ (ACS grade, Sigma-Aldrich) solution was filled into each chamber leaving $20 \mathrm{ml}$ headspace. The electrolyte was pumped through the inserted flow-through electrode assembly described above using a peristaltic pump (Fig. 1b). All experiments were performed at ambient temperature $\left(\sim 21{ }^{\circ} \mathrm{C}\right)$. Applied potentials were converted to the reversible hydrogen electrode $(\mathrm{RHE})$ scale using $E(\mathrm{RHE})=E(\mathrm{Ag} / \mathrm{AgCl})+0.2 \mathrm{~V}+$ $0.0591 \times \mathrm{pH}$ unless otherwise specified in the paper and the Biologic software was used to correct for $85 \%$ of the ohmic drop $\left(\mathrm{iR}_{\mathrm{u}}\right.$ ) of about $40 \Omega$ (as determined by impedance measurements) with the remainder being manually corrected. After each experiment, the impedance measurement was repeated to check for changes of the resistance. Under all circumstances, the resistance change was negligible. The cathode compartment was constantly purged with $\mathrm{CO}_{2}$ at a flow rate of $30 \mathrm{sccm}$, and the exhaust gases were directly purged into the inlet of a GC. All current density values are reported with respect to the geometrical area of working electrode.

\section{Gas product analysis}

Gas products formed during the $\mathrm{CO}_{2}$ electrolysis were analyzed using an in-line gas chromatograph (SRI Instruments, MultiGas Analyzer \#5) equipped with a thermal conductivity detector (TCD) for hydrogen, and a flame ionization detector (FID) for carbon monoxide. Argon was used as a carrier gas to collect hydrogen signals. Molecular Sieve 5A and HayeSep D were used in series for gas separations. The partial current density of $\mathrm{CO}$ production was calculated from GC peak area as follows

$$
J_{\mathrm{CO}}=\frac{\text { peak area }}{\alpha} \times \text { flow rate } \times \frac{2 F p_{\mathrm{o}}}{R T} \times(\text { electrode area })^{-1}
$$

where $\alpha$ is a conversion factor based on the calibration of the GC with a calibration gas standard (1000 ppm CO in argon balance), $p_{\mathrm{o}}=1.013 \mathrm{bar}$ and $T=273.15 \mathrm{~K}$. The partial current density of HER can be calculated using the same equation.

\section{Ferricyanide reduction test}

Ferricyanide reduction tests were carried out using $30 \mathrm{mM}$ $\mathrm{K}_{3}\left[\mathrm{Fe}(\mathrm{CN})_{6}\right](99 \%$, Sigma Aldrich) in $1 \mathrm{M} \mathrm{KCl} \mathrm{(ACS,} \mathrm{Sigma}$ Aldrich) supporting electrolyte using the same flow-through electrode assembly and electrolyte flow rates used for the electrochemical $\mathrm{CO}_{2}$ reduction tests, and a Pt mesh counter electrode. The potential was held constant at $-0.3 \mathrm{~V} \mathrm{vs.} \mathrm{Ag} / \mathrm{AgCl}$ in the diffusion limited regime while recording the current response as a function of flow rate. A baseline current measurement was performed in $1 \mathrm{M} \mathrm{KCl}$ at a flow rate of $10 \mathrm{rpm}$; once the current stabilized the inlet was switched to the ferricyanide electrolyte reservoir, and the effect of flow rate on the ferricyanide reduction current was measured.

\section{Author contributions}

Z. Qi: conceptualization, investigation, validation writing - original draft. S. Hawks and C. Horwood: investigation, writing - original draft. J. Biener: conceptualization, writing - review \& editing. M. Biener: conceptualization, writing - review \& editing, funding acquisition, supervision.

\section{Conflicts of interest}

There are no conflicts to declare.

\section{Acknowledgements}

IM release number: LLNL-JRNL-818910. Funding: The authors are grateful for the support of this research under the auspices of the U.S. Department of Energy under Contract DE-AC5207NA27344, through LDRD award 17-LW-013.

\section{Notes and references}

1 E. E. Benson, C. P. Kubiak, A. J. Sathrum and J. M. Smieja, Chem. Soc. Rev., 2009, 38, 89-99.

2 R. Kortlever, J. Shen, K. J. Schouten, F. Calle-Vallejo and M. T. Koper, J. Phys. Chem. Lett., 2015, 6, 4073-4082.

3 Z.-L. Wang, C. Li and Y. Yamauchi, Nano Today, 2016, 11, 373-391.

4 M. Dunwell, Q. Lu, J. M. Heyes, J. Rosen, J. G. Chen, Y. Yan, F. Jiao and B. Xu, J. Am. Chem. Soc., 2017, 139, 3774-3783.

5 L. Wang, S. Nitopi, A. B. Wong, J. L. Snider, A. C. Nielander, C. G. Morales-Guio, M. Orazov, D. C. Higgins, C. Hahn and T. F. Jaramillo, Nat. Catal., 2019, 2, 702-708. 
6 L. Wang, D. C. Higgins, Y. F. Ji, C. G. Morales-Guio, K. Chan, C. Hahn and T. F. Jaramillo, Proc. Natl. Acad. Sci. U. S. A., 2020, 117, 12572-12575.

7 X. Feng, K. Jiang, S. Fan and M. W. Kanan, J. Am. Chem. Soc., 2015, 137, 4606-4609.

8 X. Feng, K. Jiang, S. Fan and M. W. Kanan, ACS Cent. Sci., 2016, 2, 169-174.

9 H. A. Hansen, C. Shi, A. C. Lausche, A. A. Peterson and J. K. Norskov, Phys. Chem. Chem. Phys., 2016, 18, 9194-9201.

10 Q. Lu and F. Jiao, Nano Energy, 2016, 29, 439-456.

11 W. Luc, C. Collins, S. Wang, H. Xin, K. He, Y. Kang and F. Jiao, J. Am. Chem. Soc., 2017, 139, 1885-1893.

12 D. Raciti, K. J. Livi and C. Wang, Nano Lett., 2015, 15, 6829-6835.

13 D. Raciti, M. Mao, J. H. Park and C. Wang, Catal. Sci. Technol., 2018, 8, 2364-2369.

14 D. Raciti, M. Mao and C. Wang, Nanotechnology, 2018, 29, 044001.

15 Z. Qi, J. Biener and M. Biener, ACS Appl. Energy Mater., 2019, 2, 7717-7721.

16 J. J. Kim, D. P. Summers and K. W. Frese, J. Electroanal. Chem., 1988, 245, 223-244.

17 K. Hara, A. Tsuneto, A. Kudo and T. Sakata, J. Electrochem. Soc., 1994, 141, 2097-2103.

18 H. Song, M. Im, J. T. Song, J. A. Lim, B. S. Kim, Y. Kwon, S. Ryu and J. Oh, Appl. Catal., B, 2018, 232, 391-396.

19 C. F. C. Lim, D. A. Harrington and A. T. Marshall, Electrochim. Acta, 2017, 238, 56-63.

20 A. Goyal, G. Marcandalli, V. A. Mints and M. T. M. Koper, J. Am. Chem. Soc., 2020, 142, 4154-4161.

21 P. Moreno-Garcia, N. Kovacs, V. Grozovski, M. D. GalvezVazquez, S. Vesztergom and P. Broekmann, Anal. Chem., 2020, 92, 4301-4308.

22 J. B. Vennekoetter, R. Sengpiel and M. Wessling, Chem. Eng. J., 2019, 364, 89-101.

23 T. Burdyny and W. A. Smith, Energy Environ. Sci., 2019, 12, 1442-1453.

24 D. Higgins, C. Hahn, C. X. Xiang, T. F. Jaramillo and A. Z. Weber, ACS Energy Lett., 2019, 4, 317-324.

25 B. Endrődi, E. Kecsenovity, A. Samu, F. Darvas, R. V. Jones, V. Török, A. Danyi and C. Janáky, ACS Energy Lett., 2019, 4, 1770-1777.

26 L.-C. Weng, A. T. Bell and A. Z. Weber, Energy Environ. Sci., 2019, 12, 1950-1968.

27 M. de Jesus Gálvez-Vázquez, P. Moreno-García, H. Xu, Y. Hou, H. Hu, I. Z. Montiel, A. V. Rudnev, S. Alinejad, V. Grozovski, B. J. Wiley, M. Arenz and P. Broekmann, ACS Catal., 2020, 10, 13096-13108.

28 Z. Qi, M. M. Biener, A. R. Kashi, S. Hunegnaw, A. Leung, S. C. Ma, Z. Y. Huo, K. P. Kuhl and J. Biener, J. CO2 Util., 2021, 45, 101454, DOI: 10.1016/j.jcou.2021.101454.

29 D. M. Weekes, D. A. Salvatore, A. Reyes, A. X. Huang and C. P. Berlinguette, Acc. Chem. Res., 2018, 51, 910-918.

30 Y. K. Chen, N. S. Lewis and C. X. Xiang, J. Electrochem. Soc., 2020, 167, 114503.
31 N. C. Kani, A. Prajapati, B. A. Collins, J. D. Goodpaster and M. R. Singh, ACS Catal., 2020, 10, 14592-14603.

32 K. Liu, W. A. Smith and T. Burdyny, ACS Energy Lett., 2019, 4, 639-643.

33 D. Corral, J. T. Feaster, S. Sobhani, J. R. DeOtte, D. U. Lee, A. A. Wong, J. Hamilton, V. A. Beck, A. Sarkar, C. Hahn, T. F. Jaramillo, S. E. Baker and E. B. Duoss, Energy Environ. Sci., 2021, 14, 3064-3074.

34 J. J. L. Humphrey, D. Plana, V. Celorrio, S. Sadasivan, R. P. Tooze, P. Rodriguez and D. J. Fermin, ChemCatChem, 2016, 8, 952-960.

35 M. Clark and C. Kubiak, Abstr. Pap. Am. Chem. Soc., 2016, 252, 54.

36 C. Z. Chen, B. Zhang, J. H. Zhong and Z. M. Cheng, J. Mater. Chem. A, 2017, 5, 21955-21964.

37 V. Vedharathinam, Z. Qi, C. Horwood, B. Bourcier, M. Stadermann, J. Biener and M. Biener, ACS Catal., 2019, 10605-10611, DOI: 10.1021/acscatal.9b03201.

38 C. Zhu, Z. Qi, V. A. Beck, M. Luneau, J. Lattimer, W. Chen, M. A. Worsley, J. C. Ye, E. B. Duoss, C. M. Spadaccini, C. M. Friend and J. Biener, Sci. Adv., 2018, 4, eaas9459.

39 Z. Qi, M. M. Biener, A. R. Kashi, S. Hunegnaw, A. Leung, S. C. Ma, Z. Y. Huo, K. P. Kuhl and J. Biener, Mater. Res. Lett., 2021, 9, 99-104.

40 K. G. Schulz, U. Riebesell, B. Rost, S. Thoms and R. E. Zeebe, Mar. Chem., 2006, 100, 53-65.

41 W. Li, G. Yu and Z. Yu, Appl. Therm. Eng., 2020, 179 115686.

42 J. Biener, A. Wittstock, L. A. Zepeda-Ruiz, M. M. Biener, V. Zielasek, D. Kramer, R. N. Viswanath, J. Weissmuller, M. Baumer and A. V. Hamza, Nat. Mater., 2009, 8, 47-51.

43 A. J. Martín, G. O. Larrazábal and J. Pérez-Ramírez, Green Chem., 2015, 17, 5114-5130.

44 D. M. Weekes, D. A. Salvatore, A. Reyes, A. X. Huang and C. P. Berlinguette, Acc. Chem. Res., 2018, 51, 910-918.

45 M. R. Singh, E. L. Clark and A. T. Bell, Phys. Chem. Chem. Phys., 2015, 17, 18924-18936.

46 M. R. Singh, Y. Kwon, Y. Lum, J. W. Ager and A. T. Bell, J. Am. Chem. Soc., 2016, 138, 13006-13012.

47 K. J. P. Schouten, E. P. Gallent and M. T. M. Koper, J. Electroanal. Chem., 2014, 716, 53-57.

48 J. Qiao, Y. Liu, F. Hong and J. Zhang, Chem. Soc. Rev., 2014, 43, 631-675.

49 W. T. E. van den Beld, M. Odijk, R. H. J. Vervuurt, J.-W. Weber, A. A. Bol, A. van den Berg and J. C. T. Eijkel, Sci. Rep., 2017, 7, 45080.

50 E. L. Clark, J. Resasco, A. Landers, J. Lin, L. T. Chung, A. Walton, C. Hahn, T. F. Jaramillo and A. T. Bell, ACS Catal., 2018, 8, 6560-6570.

51 S. J. Konopka and B. McDuffie, Anal. Chem., 1970, 42, 1741-1746.

52 G. W. C. Kaye and T. H. Laby, Tables of Physical and Chemical Constants, Longman Publishing Group, New York, 15th edn, 1986. 